\title{
0 mosaico dos poderes públicos em zona costeira numa região ultraperiférica da União E uropeia: o caso da criação dos recifes artificiais na Martinica
}

\section{The mosaic of public authorities in the coastal area of an Outermost Region of the European Union: the case of the creation of artificial reefs in Martinique}

\author{
Pierre Angelelli ${ }^{1}$, Pascal Saffache ${ }^{@}$
}

\section{RESUMO}

Situada no centro do arco das Pequenas Antilhas a leste do Mar do Caribe, a Martinica é uma ilha com $1.100 \mathrm{~km}^{2}$. Ela faz parte integrante da República francesa e da União Europeia, onde é reconhecida como uma das sete regiões ultraperiféricas, com as ilhas Canárias (Espanha), a Madeira e os Açores (Portugal).

Um projecto de recifes artificiais foi iniciado no ano 2000 para facilitar o repovoamento haliêutico e permitir, após um período de interrupção da pesca, uma exploração optimizada.

Este artigo pretende mostrar que, em termos de gestão costeira, a criação de recifes artificiais na Martinica é interessante porque é um exemplo de fragmentação e sobreposição de responsabilidades a nível local, nacional, europeu e internacional e de divergências entre os objectivos ambientais e os objectivos de exploração económica. O "mosaico" dos poderes públicos e a evolução dos objectivos aumentam a dificuldade de participação dos pescadores profissionais na implementação de recifes artificiais - e, de maneira mais geral, a dificuldade em associar os utilizadores do mar a um programa de gestão costeira.

Paradoxalmente, esta situação contém em si soluções inovadoras para a "governação" das zonas costeiras na Europa. Com efeito, contrariamente aos Estados independentes ou aos territórios autónomos das Pequenas Antilhas, na Martinica

@ - autor correspondente - pierre.angelelli@ martinique.univ-ag.fr; $\infty$-autor: pascal.saffache@ martinique.univ-ag.fr

1 - Centre d E tude et de Recherche en E conomie, G estion, Modélisation et Informatique A ppliquée - Center for research and studies in economics, mark eting, modelisation and applied computer science (CE RE G M IA - E A 2440) - U niversité des A ntilles et de la G uyane, U niversidade A ntilhas e G uiana, campus de Schoelcher, BP 7207, 97275 Schoelcher C edex, Martinique (FW I), Phone : 05.96.72.74.00, Fax : 05.96.72.74.03.

* Submissão - 4 M aio 2009; A valiação - 15 Junho 2009; Recpção da versão revista - 270 utubro 2009; D isponibilização on-line - 18 Janeiro 2010 


\author{
A ngelelli \& Saffache \\ Revista de G estão C osteira Integrada / Journal of Integrated C oastal Z one Management 10(1):65-80 (2010)
}

a unidade institucional do meio marinho pode ser obtida por um suplemento de procedimentos ea utilização de instrumentos complexos da União europeia.

Palavras-chave: recifes artificiais, gestão costeira, fragmentação e sobreposição de responsabilidades, instrumentos de gestão

\begin{abstract}
$\mathrm{L}$ ocated at the entre of the arc of the $\mathrm{L}$ esser $\mathrm{A}$ ntilles in the $\mathrm{E}$ ast of the $\mathrm{C}$ aribbean Sea, Martinique is an island of $1.100 \mathrm{~km} 2$. It is part of the French Republic and also of the $\mathrm{E}$ uropean $\mathrm{U}$ nion where it is reoogniz ed like one of the seven $\mathrm{O}$ utermost Regions, with the $\mathrm{C}$ anary islands (Spain), Madeira and the A zores (Portugal).

A project of artificial reefs was initiated sinœ 2000 to facilitate fish repopulation and allow, after a period of interruption of fishing, an optimal ex ploitation.

The purpose of this paper is to show that, in terms of coastal management, the creation of artificial reefs in Martinique is interesting because it is an ex ample of fragmentation and superposition of public responsibilities on local, national, E uropean and international level, and divergenoes between the environmental and economic objectives. The "mosaic" of the public authorities and the evolution of the objectives increase the difficalty of participation of the professional fishermen in the creation of the artificial reefs - and, in a more general way, the problem to associate the users of the sea to coastal management.

Paradox ically, this situation contains in it innovating solutions for the "governane" of the coastal areas in E urope. Indeed, œntrary to the independent States or non-self-governing Territories of the L esser A ntilles, in M artinique the institutional unity of the sea can be obtained by a supplement of procedure and the use of complex instruments of the $\mathrm{E}$ uropean $\mathrm{U}$ nion.
\end{abstract}

Keywords: artificial reefs, coastal management, fragmentation and superposition of responsibilities, management instruments

\section{INTRODUÇÃO}

Situada no centro do arco das Pequenas Antilhas (ou Índias O cidentais) a leste do Mar do Caribe e enquadrada pelas ilhas da D ominica a Norte e a Santa Lúcia a Sul, a Martinica é uma ilha de 400.000 habitantes com uma superficie de $1.100 \mathrm{~km}^{2}$.

A Martinica tem o estatuto de D épartement français d'0 utre mer (D epartamento francês ultramarino) desde 1946 e faz parte integrante da República francesa e da União Europeia, onde é reconhecida como uma das sete regiões ultraperiféricas, com a $\mathrm{G}$ uadalupe, a Guiana francesa, a ilha da Reunião no O ceano Índico, as ilhas Canárias (Espanha), a Madeira e os Açores (Portugal).

Este artigo pretende mostrar que, em termos de gestão costeira, a implementação de recifes artificiais na Martinica é interessante porque é um exemplo de fragmentação e sobreposição de responsabilidades a nível local, nacional, europeu e internacional. Paradoxalmente, este complexo "mosaico" contém em si soluções inovadoras para a governança das zonas costeiras.
O artigo está estruturado como segue:

I. Descrição do projeto

- Quadro geral

- Descrição do projeto e os procedimentos seguidos

II. Contexto legal e administrativo dos recifes artificiais em Martinica

- Contexto Nacional

- Contexto Europeu

- Contexto Internacional

III. Identificação e análise das questões-chave - Mosaico dos poderes públicos e fragmentação das decisões

- Divergências entre os objectivos ambientais e os objectivos de exploração económica

- Participação dos pescadores profissionais

IV. Perspectivas de soluções - Conclusões. 


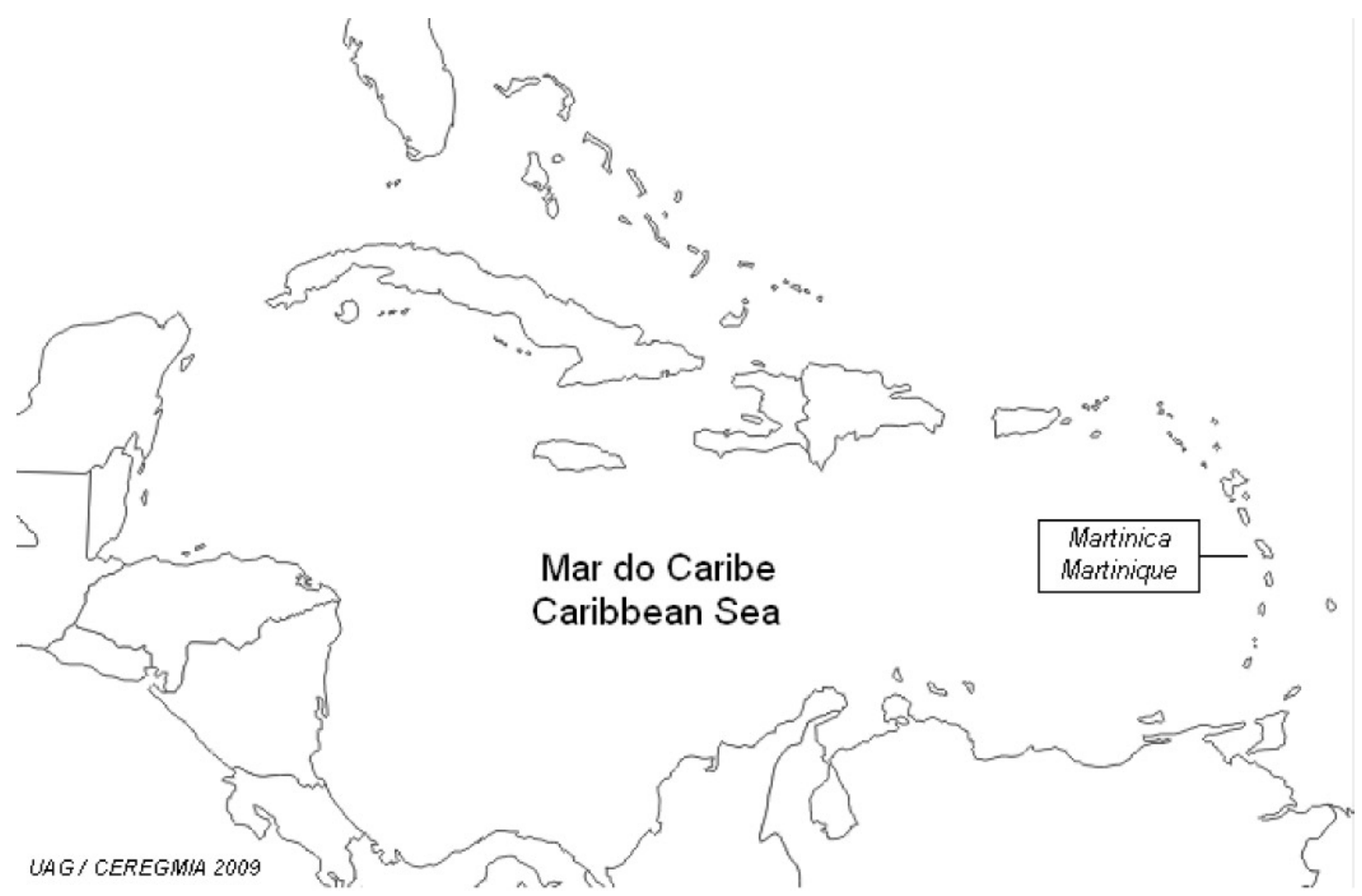

Figura 1. Mapa geral do Mar do Caribe.

Figure 1. $G$ eneral chart of the $C$ aribbean Sea.

\section{DESCRIÇÃO DO PROJECTO}

De acordo com uma das definições geralmente admitidas, os recifes artificiais são estruturas imersas colocadas deliberadamente no fundo do mar para imitar as características naturais (Baine, 2001). Mas os objectivos visados (repovoamente dos fundos marinhos para benefício da pesca (Neves Santos \& Costa Monteiro, 1998); aquicultura extensiva(Seaman, 2007); protecção dos fundos contra actividades de pesca de arrasto; conservação das espécies; valorização de sítios para mergulho (Van Treeck \& Schuhmacher, 1998) ou actividades recreativas (Sutton \& Bushnell, 2007); luta contra a erosão costeira (Ten Voorde et al., 2008); protecção contra tsunamis; ajuda à reconstituição de corais naturais (O ren \& Benayahu, 1997), etc.) e os meios utilizados podem tornar difícil a avaliação dos resultados e criar efeitos contraditórios (Morton, 1996).

Na Martinica, a vontade de gerir e aumentar os recursos haliêuticos em benefício dos pescadores foi o motivo essencial da criação de recifes. Contudo, as medidas de limitação de pesca associadas aos recifes - e em especial o acoplamento da sua implantação com as áreas marinhas protegidas - inseriram-se, na prática, numa política geral de protecção do ambiente marinho apoiado aos níveis francês, europeu e internacional.

\subsection{Quadro geral}

Na Martinica, a pesca praticada para um mercado local por um milhar de profissionais que trabalham mais de 99\% deles a bordo de barcos de dimensão inferior a 12 metros apresenta características próximas da praticada nas outras ilhas do arco das Pequenas Antilhas (Brown \& Pomeroy, 1999). Com efeito, tratase das mesmas espécies alvo (peixes, crustáceos e moluscos dos recifes coralinos, peixes pelágicos); das mesmas técnicas e engenhos de pesca (barcos 
frequentemente pequenos, com saídas de menos de 24 horas, com utilização de linhas e de redes, e, num período recente, do desenvolvimento de novas técnicas como os engenhos de concentração de peixes); de fraca estruturação da profissão, e de baixa centralização dos locais de desembarque dos produtos da pesca.

O s profissionais da pesca lamentam-se de maneira recorrente de uma baixa dos desembarques de produtos da pesca. A ideia foi criar recifes susceptíveis, por um lado, de aumentar o rendimento em zonas não coralinas pouco povoadas - permitindo uma reprodução dos peixes adultos através da protecção de lugares de postura, reunindo espécies dispersas para favorecer a captura - e, por outro lado, de diminuir os custos - pela diminuição dos tempos de trajecto e de investigação. Esta ideia concretizou-se no fim dos anos '90.

Por razões práticas, a implantação de recifes registou-se em paralelo com a criação de áreas marinhas protegidas onde qualquer forma de pesca era proibida. Tratava-se de completar o dispositivo geral de redução do esforço de pesca na faixa costeira e da reorganização da pesca artesanal para os engenhos de concentração de peixes implantados ao largo (Laisné \& Angelelli, 2000). Tratava-se também de tirar partido da criação pelo governo francês de áreas marinhas protegidas na ilha (Sygut, 2006), a fim de implantar recifes sem ter de recorrer novas proibições.

A partir do fim dosanos ' 60 foram realizadas vánias experiências em França: carroçarias de automóveis foram assim imersas ao largo das costas mediterrânicas francesas para repovoamento haleûtico. Perseguindo o mesmo objectivo, a Région Languedoc-Roussillon tomou a iniciativa de implantar também (desde 1984) recifes em 5 locais (Pary, 2004). Mais recentemente, a Cidade de Marselha decidiu implantar 35.000 metros cúbicos de estruturas artificiais sobre uma superfície de cerca de 200 hectares (a uma profundidade de $30 \mathrm{~m}$ ) com 0 objectivo de criar "um novo ecossistema"!

\subsection{Descrição do projeto e os procedimentos seguidos}

0 projecto de construção de recifes artificiais foi iniciado em 2000 pelo C onseil Régional de la M artinique
(Conselho Regional da Martinica) para apoiar o sector da pesca artesanal.

Concretamente, o projecto consistiu na imersão de 4 recifes artificiais em zonas marinhas protegidas Baía da Trinité/ Sainte-Marie e Baía do Robert (na costaA tlântica da ilha), e "Ilet-à-Ramiers" (Trois-Ilets) e Case-Pilote, na costa do Caribe. Estes recifes têm em comum uma forma caótica piramidal com um volume de cerca de $500 \mathrm{~m}^{3}$ e uma área de ancoragem de menos de $2000 \mathrm{~m}^{2}$. Em contrapartida, as profundidades de imersão são diferentes, em conformidade com os fundos locais entre as cotas -7 $\mathrm{m}$ e $-30 \mathrm{~m}$, assim como os materiais constituintes: três recifes são constituídos por rochas naturais e 0 quarto por betão e tubos.

0 custo total dos 4 recifes foi de aproximadamente 230.000 euros (320.000 USD). A União Europeia interveio com uma comparticipação até 75\% das despesas através do Conseil Régional. 0 financiamento foi totalmente de origem pública, tendo em conta 0 carácter experimental do projeto e a dificuldade em atribuir os custos e em avaliar e individualizar as receitas directas e indirectas.

O Conseil Régional confiou ao Comité Régional des Pêches maritimes et des E levages marins (CR PMEM), organismo semipúblico representando os pescadores, a realização da operação.

A verificação dos rendimentos dos recifes artificiais é contudo recente, devido à complexidade dos habitats artificiais; estes permitem aumentar até 40 vezes a biomassa (Charbonnel et al., 2002) e antecipar em meio tropical uma produção anual muito mais rica que nos recifes coralinos, sendo de encarar uma valorização económica directa para a pesca ou indirecta (aumento do recrutamento de peixes e das capturas em redor do recife ou ainda melhoria da qualidade das águas (Whitmarsh et al., 2008)).

Segundo os biólogos do projecto "Estas estruturas, verdadeiros oásis do mar, permitiram a instalação de novos ecossistemas produtivos e diversificados sobre desertos de areia. A abundância das populações de peixes adultos ou jovens ultrapassa a que encontramos nos recifes coralinos" (Barnabé, 2007).

Um projecto de implantação de recifes artificiais inclui dois aspectos: administrativo e financeiro, com sequências distintas, sendo importante entender que 


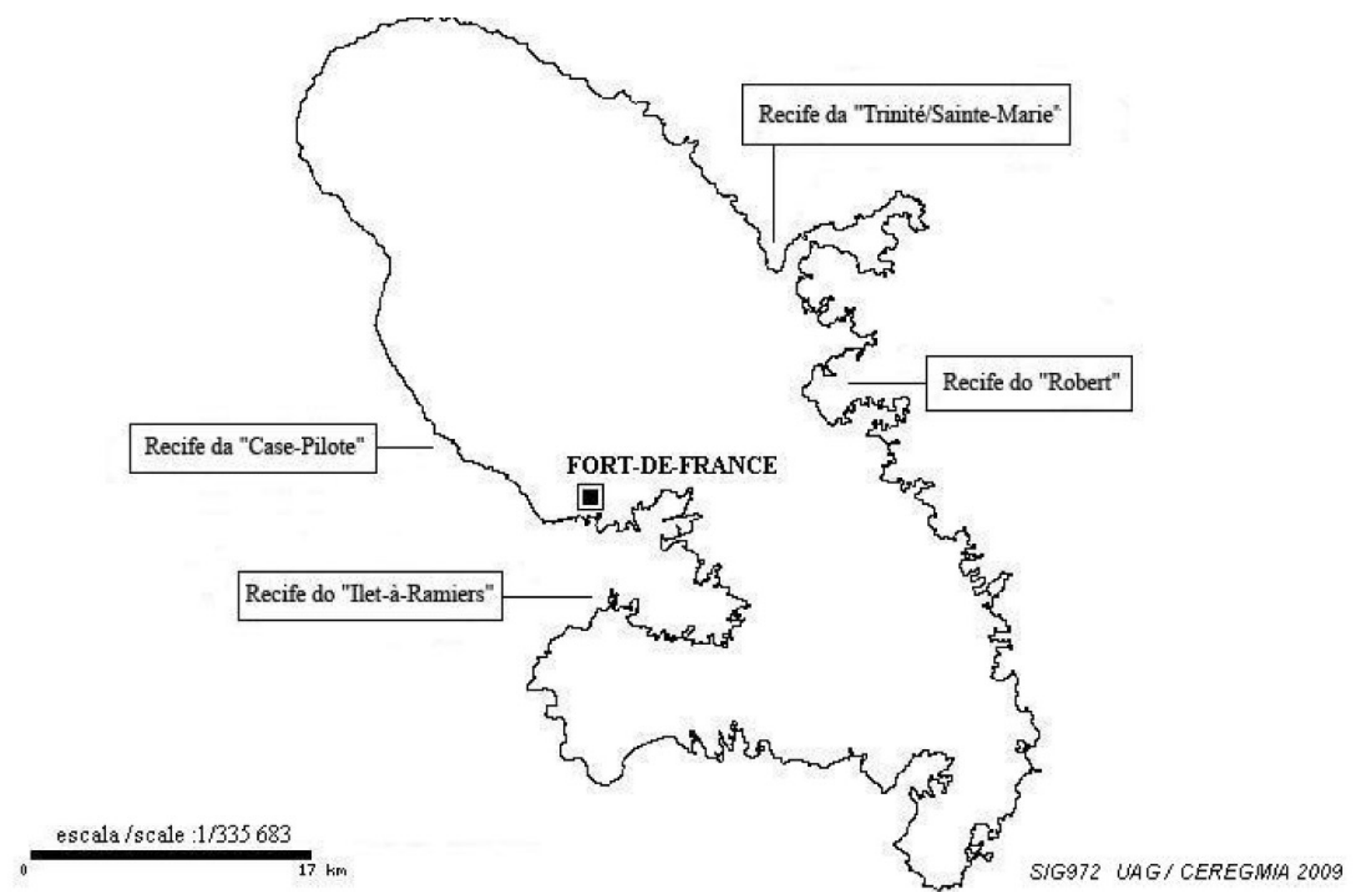

Figura 2. Mapa de Martinica com a localização geral dos recifes artificiais.

Figure 2. Chart of Martinique with the indication of the artificial reefs.

o status de departamento ultramarino não significa que tenha mais autonomia. Significa, pelo contrário, que as leis aprovadas pelo parlamento francês são aplicáveis em todos os D épartements da Europa continental e ultramarina, apelando a uma integração mais forte ao território nacional.

Aspecto administrativo. A implantação de recifes artificiais no fundo do mar territorial necessita de autorizações de imersão atribuídas pelo representante local do governo central (Préfet) após um procedimento especial dito de "criação de estabelecimentos de pesca marítima".

Um pedido é formulado pelo CRPMEM e submetido a um procedimento de instrução conduzido pelos serviços dos Assuntos Marítimos; este procedimento consiste numa longa consulta e pareceres das autoridades públicas responsáveis. No final da instrução, o Préfet emite a "concessão". Q uatro anos após o arranque do projecto (2004), as concessões para a implantação dos 4 recifes da Martinica foram atribuídas para uma duração de 5 anos.

Por último, um terceiro procedimento administrativo relativo às imersões no mar de destroços não foi conduzido devido à natureza de recifes artificiais - que não são nem escombros de dragagens nem detritos mas "depósitos de matérias destinados a outros fins para além da sua simples eliminação" (Nações Unidas, 1982b).

Aspecto financeiro. A estas obrigações administrativas ligadas à implantação dos recifes, acrescentam-se procedimentos de financiamento da operação.

Após a descentralização (abaixo 3.1. Contexto nacional), o Conseil Régional assegura por si só o financiamento da parte nacional dos projetos de desenvolvimento da pesca e da aquacultura. 0 governo central deixa de intervenir, mas continua a gerir os fundos europeus. 
$\mathrm{Na}$ Martinica, devido ao afastamento e à insularidade - como noutras regiões europeias ultramarinas -, a União Europeia credita a implantação dos recifes artificiais com subvenção de $75 \%$ aos " trabalho anteriores à implantação, incluindo os estudos, [...] os componentes, [...] a sinalização, [...] o transporte e [...] a montagem das instalações, bem como [...] o acompanhamento científico" (União Europeia, 2007).

A sequência do tratamento financeiro do projecto apresenta-se normalmente desta maneira. Um pedido de concurso financeiro é formulado junto do $C$ onseil Régional pelo CRPMEM. Uma comissão dita "sectorial" composta por eleitos políticos decide atribuir o financiamento em nome do Conseil Régional. Depois, uma outra comissão especializada presidida pelo Préfet intervem para formular um parecer técnico antes da consulta da comissão "interfundos", designada para gerir os fundos atribuídos pelo ministério da Agricultura e da Pesca à Martinica, ao título do Fundo Europeu para as Pescas (FEP).

\section{CONTEXTO LEGAL E ADMI- NISTRATIVO DOS RECIFES ARTIFICIAIS EM MARTINICA}

\subsection{Contexto nacional}

Até ao fim dos anos '70, a França era dirigida por um governo central que agia directa ou indirectamente pelos seus serviços locais (Préfectures ou serviços ditos "técnicos" que representam os ministérios). As Communes (Munícipios) e os D épartements (D epartamentos) eram as únicas entidades territoriais (C ollectivités locales) e tinham pouca autonomia.

A Martinica era antes de 1946 uma das colónias francesas. Estas colónias ultramarinas, que contribuíram para a vitória contra a Alemanha e os seus aliados, viram reconhecido pela Metrópole (França continental) um direito à emancipação. Neste quadro, a Martinica obteve o estatuto de departamento francês ultramarino (a "départementalisation") para dar aos seus habitantes os mesmos direitos que os da França metropolitana e, consequentemente, reforçar a integração na República francesa.

A partir dos anos '80, a França relançou um vasto programa destinado a transferir uma parte do poder do governo central para as entidades territoniais eleitas - D épartements e Communes - ao qual se acrescentaram as Régions. Nalguns processos de planeamento, relativos a territórios que apresentam especificidades - como Paris, a Córsega, as entidades ultramarinas -, esta dinâmica foi idêntica para todas as entidades territoriais eleitas. Importa notar que, desde esta época, e como nos outros D épartements d'outremer (G uadalupe, G uiana, Reunião), a Martinica acumula sobre o mesmo território umaRégion e um D épartement.

$\mathrm{Na}$ prática, no sector da pesca, ou mais amplamente no sector do mar, as Régions (Conseils régionaux ) receberam as atribuições em matéria de desenvolvimento económico. No domínio marítimo, os D épartements ocuparam-se doravante da gestão dos portos de pesca e os Communes "herdaram" do governo central a gestão dos portos comunais. As competências dos Communes em matéria de regulamento de banhos e de actividades náuticas na faixa litoral dos 300 metros, sob reserva dos poderes conferidos a outras autoridades do governo central, foram igualmente clarificadas.

Além disso, a Martinica, a exemplo das outras Regiões ultramarinas, obteve do governo central as competências de regulamentação das pescas marítimas em mar territorial, mas estas competências transferidas em 2000 necessitam da publicação de decretos de aplicação que não foram dispensados pelo governo central (G overno francês, 2000).

O governo central reorganizou igualmente em 1991-1992 a representação profissional do sector da pesca com o Comité régional des Pêches maritimes et des E levages marins (CRPMEM).

Paralelamente a este processo de descentralização, há um crescente envolvimento das instituições europeias, o que reforça o efeito de "mosaico" da organização dos poderes públicos, particularmente na zona costeira.

\subsection{Contexto europeu}

\subsubsection{Objectivo europeu de exploração dos recursos das pescas}

Não prevista inicialmente pelo Tratado de Roma de 1957, que institui a Comunidade Económica Europeia, a política comum das pescas vai emergir desde os anos '70 e tomar uma dimensão directamente 
vinculativa para os pescadores (União Europeia, 1983). Em termos de metodologia, esta política vai cobrir um aspecto de incentivo, constituído por subvenções ligadas quer ao apoio dos mercados dos produtos da pesca, quer à realização de programas, e um aspecto normativo ou coercivo, ligado à promulgação pela União Europeia de regras impostas directa ou indirectamente aos profissionais da pesca.

Em matéria de recifes artificiais, a intervenção da União Europeia apresenta três caracteres: não faz apelo primordial ao regulamento, mas antes ao estímulo financeiro; as normas europeias que dizem respeito às águas litorais são, desde a origem, sobretudo medidas que resultam da conservação do meio ambiente terrestre e de água doce, mais do que medidas de gestão costeira. Por último, as medidas específicas da gestão do ambiente costeiro são influenciadas fortemente pelas convenções internacionais.

A competência europeia afirmou-se em matéria de exploração dos recursos de pesca através da regulamentação das actividades de alto mar, da coabitação entre as diferentes frotas europeias e da partilha dos recursos haliêuticos comuns. Mas, essencialmente, os Estados europeus ficaram livres para regulamentar, eles próprios, o núcleo das actividades na faixa costeira.

As normas europeias no domínio marítimo continuam a ser reservadas sobretudo aos "elementos móveis", ou que participam na mobilidade das pessoas, mercadorias ou factores de produção que interessam ao território da União e ao Mercado único.

Os aspectos "marítimos" ou "marinhos" não possuem a mesma mobilidadee, por conseguinte, não intervêm ao mesmo nível na realização do mercado interno europeu, estando principalmente dependentes dos programas de ajuda financeira e da livre escolha dos governos europeus (orientados pelas entidades territoriais, pelos interesses privados ou pelas organizações não governamentais). Assim, os recifes artificiais, devido ao fraco papel no Mercado único e igualmente à massa dos interesses divergentes a coordenar, estão dependentes dos mecanismos europeus de incentivo financeiro.

A partir de 1986, a vertente normativa da política europeia das pescas foi complementada por uma vertente financeira. A noção de recife artificial, na falta do termo, é precisada a partir do Regulamento europeu de 1986, que considera "que é oportuno que zonas costeiras sejam protegidas através da instalação de estruturas artificiais destinadas a facilitar a repovoamento haliêutico e a permitir, após um período de interrupção da pesca, uma exploração óptima dessas zonas"; em consequência (União Europeia, 1986), é fixado que "1. A Comissão [europeia] pode conceder apoio financeiro comunitário a projectos públicos, semipúblicos ou privados relativos: (... ) b) as acções de protecção e de valorização das zonas marinhas costeiras através da instalação, aquém da isóbata de 50 metros, de elementos fixos ou móveis destinados a delimitar zonas protegidas e a permitir a protecção ou 0 desenvolvimento dos recursos haliêuticos".

O Regulamento de 2006 relativo ao Fundo Europeu para as Pescas (FEP) confirma o apoio aos recifes com a dupla vocação de desenvolvimento dos recursos aquáticos e melhoramento do meio ambiente (União Europeia, 2006).

Os fundos europeus podem ser solicitados em complemento de uma subvenção da Région para os projectos, tais como os recifes artificiais. 0 Instrumento Financeiro de Orientação das Pescas (União Europeia, 1999) participou até $75 \%$ do custo total do projeto. Estes fundos (IFOP e FEP) são distribuídos pelo Préfet.

\subsubsection{Objectivo europeu de protecção do ambiente maninho}

Paralelamente às medidas de incentivo financeiro, foram implementadas normas europeias que interessam às águas litorais, mas resultam sobretudo da preservação do ambiente terrestre e, para simplificar, da "água doce", mais do que das medidas de gestão costeira. Na União Europeia (e, portanto, na Martinica), as medidas de gestão costeira permanecem assuntos nacionais.

A revisão da política europeia das pescas preparada pelo Conselho de Santa Maria da Feira (Portugal) de 2000 confirmou a integração das preocupações ambientais na política das pescas, em conformidade com o Tratado que instituiu a Comunidade Europeia (União Europeia, 1997).

Nesta perspetiva, a União Europeia colocou em destaque quatro domínios "terrestres" deintervenção 
que têm um impacto sobre a gestão costeira: a redução da poluição do meio aquático (União Europeia, 1976b), a qualidade das águas balneares (União Europeia, 1976a), a qualidade das águas conquícolas (para as criações em mar dos mexilhões, ostras e outros mariscos) (União Europeia, 1979) e a recolha, o tratamento e a rejeição das águas urbanas residuais, bem como o tratamento e a rejeição das águas usadas que provêm de sectores industriais (União Europeia, 1991). A pesar das águas costeiras serem aqui objecto de uma definição ampla (União Europeia, 1991), elas são encaradas unicamente como o meio receptor de poluições provenientes de terra e geridas no âmbito de bacias hidrográficas.

Com a "Directiva-Quadro no domínio da água" que se refere às águas doces, mas igualmente às águas costeiras situadas até "uma distância de uma milha marinha para além do ponto mais próximo da linha de base" (União Europeia, 2000a), a União Europeia efectuou em 2000 uma vasta síntese qualificada de "política integrada" (União Europeia, 2000b): (i) da protecção das águas destinadas ao consumo humano, (ii) das espécies aquáticas, (iii) das águas balneares, (iv) dos habitats e das espécies envolvidas nos sítios da rede $\mathrm{N}$ atura 2000 (União Europeia, 1992), (v) do tratamento das águas urbanas residuais e (vi) dos seus compromissos internacionais em matéria de poluição do meio marinho. Principalmente consagrado às águas doces, a Directiva-Quadro no domínio da água integra, com instrumentos de medida mas sem verdadeiros instrumentos de gestão, as águas territoriais inclusive as águas costeiras num dispositivo terrestre de "distritos hidrográficos".

\subsection{Contexto internacional}

0 contexto internacional das medidas de gestão do ambiente marinho e costeiro (D esse \& Saffache, 2005) foi fornecido pelo primeiro relatório sobre 0 estado do ambiente no mundo, estabelecido em 1951 pela União Internacional para a Conservação da Natureza e dos Recursos Naturais (UICN International U nion for Conservation of $\mathrm{N}$ ature), e a sucessão das iniciativas mundiais de 1972, 1982, 1992 e 2002: o Programa das Nações Unidas para o Meio Ambiente(PNUMA), resultante da Conferência sobre o ambiente reunida em Estocolmo em 1972, a Conferência mundial sobre 0 ambiente e 0 desenvolvimento realizada no Rio de Janeiro em 1992 (Saffache \& Moutamalle, 2006) - e o famoso capítulo 17 da agenda 21, interessando simultaneamente a gestão integrada das zonas costeiras e 0 desenvolvimento sustentável das pequenas zonas insulares - a Cimeira mundial sobre 0 desenvolvimento sustentável reunida em Joanesburgo em 2002 - e as suas temáticas sobre as ilhas, os oceanos e a biodiversidade - e, entretanto, a Convenção das Nações Unidas sobre o direito do mar celebrada em Montego Bay (Jamaica) em 1982.

Esta última convenção coloca o direito soberano dos Estados a explorar os respectivos recursos naturais "em conformidade com o dever de proteger e preservar o meio marinho" (Nações Unidas, 1982c). Mas apresenta igualmente um interesse do ponto de vista da gestão dos recifes artificiais, definindo, por um lado, de maneira universal - e simbolicamente no seu artigo primeiro - "a poluição do meio marinho" (Nações Unidas, 1982a) e, por outro, permitindo um tratamento especial para as implantações de recifes, cuja Convenção nos diz que, por excepção à definição comum e à obrigação dos Estados de "prevenir, reduzir e dominar a poluição do meio marinho por imersão" (Nações Unidas, 1982d), "o termo "imersão" não visa "o depósito de matérias para outros fins que não sejam os da sua simples eliminação" (Nações Unidas, 1982b).

O PNUMA, quanto a ele, permitiu regionalizar a luta contra a poluição proveniente de navios ou de terra bem como a conservação dos ecossistemas marinhos e das espécies nos mares regionais. A Martinica, à semelhança das outras ilhas das Antilhas (Singh \& Mee, 2008), está envolvida pela Convenção para a protecção e desenvolvimento do ambiente marinho na região das Caraíbas dita "Convenção de Cartagena", adoptada em 1983, e pelo respectivo Protocolo, adoptado em Kingston em 1990, que estende aos ecossistemas, e não unicamente às espécies, a obrigação de protecção da biodiversidade marinha e tenta equilibrar os objectivos ecológicos e económicos.

As Convenções de Montego Bay e de Cartagena são doravante "pilares" importantes tanto dos textos europeus como dos textos franceses em matéria de protecção do ambiente litoral e da imersão no mar de desperdícios e de outras matérias. 


\section{IDENTIFICACÃO DAS QUEST ÕES- CHAVE NA CRIAÇÃO DE RECIFES EM MARTINICA, E ANÁLISE SUMÁRIA}

\subsection{Mosaico dos poderes públicos e fragmentação das decisões}

A França não escapa por conseguinte a uma realidade descrita por Ehler (Ehler, 2003): "M ost countries continue to manage their ocean resouros and space on a sector-by-sector regulatory basis. 0 ne law, one agency, and one set of regulations may be applicable to a singlepurpose regime (e.g., oil and gas development, fisheries, water quality, navigation, or protecting endangered species), and a single ocean area may be subject to a plethora of regulatory management regimes ».(... ) "The fragmentation of governmental agencies is both horizontal and vertical. A t the present time, management of the marine environment is carried out at local, state, regional and national (and, in some cases, marine transportation, for example, international) levels of government. A t any given level, various functions arecarried out by a widearray of separate agencies and organizations, with limited or sporadiccoordination. A sa result, fragmentation is the general ruleand many situations are poorly or inefficiently managed."

A tabela 1 resume de maneira não exaustiva a repartição das principais competências das autoridades públicas, em relação à problemática dos recifes artificiais na Martinica.

Contrariamente às outras economias insulares que lhe são comparáveis em tamanho, a "co-gestão" da zona costeira na Martinica não se limita a partilhar a responsabilidade entre o governo e os grupos de interesses (Pomeroy et al., 2004). Vários elementos devem ser realçados.

Primeiro, a fragmentação das competências caracteriza a estrutura do Estado em França (D auvin et al., 2004) e, portanto, na Martinica.

A terra de Montesquieu e da separação de poderes conhece uma separação vertical clássica (legislativo, executivo, judicial) detalhada, ao nível do executivo pela existência de mais de quarenta departamentos ministeriais e mais de 200 direcções centrais. A esta separação vertical acrescenta-se uma separação horizontal recente com a autonomia das Communes, os D épartements e as Régions, seguindo-se a emergência dos poderes públicos europeus, eles mesmos fraccionados num poder legislativo (compartilhado entre o Conselho que representa os governos centrais e o Parlamento que representa os cidadãos europeus), um poder executivo detido pela Comissão europeia (Comissários europeus, D ireções-G erais e agências executivas), um poder judicial nas mãos do Tribunal de Justiça, e um Banco central independente.

Apesar da separação horizontal, a herança institucional da colonização seguidamente à départementalisation de 1946 (3.1.) conduz frequentemente a procurar uma solução para os problemas internos da Martinicajunto de autoridades externas (governo central - Préfet e serviços técnicos do governo central; ministérios em Paris - e, cada vez mais, a União europeia). É assim para certos conflitos sociais como para a gestão costeira.

De facto, o segundo elemento reside nas modalidades da coordenação. A fragmentação implica que, na maioria dos casos, as instituições devem agir juntas para a realização de um projecto, em particular no domínio dos recifes artificiais.

Formalmente, a integração revestirá a forma de uma coordenação, que combinará três categorias de escolhas:

- a coordenação poderá ser explícita, se for objecto de uma co-decisão ou de uma parceria fundamentando-se em objectivos comuns, ou, mais geralmente, implícita com base numa instruction administrative (instrução administrativa): um projecto é examinado sucessivamente por diferentes serviços administrativos ou de financiamento, exprimindo um parecer no respectivo domínio de competências;

- a coordenação poderá ser de tipo incitativo, se for objecto de uma ajuda financeira pública, ou de tipo normativo, caso se traduza no acordo ou na recusa de uma autorização;

- porúltimo, a coordenação poderáfazer intervir um ou diferentes níveis geográficos: local, central ou europeu.

Estes tipos de coordenação, requeridos pela fragmentação de competências, contribuíram por um lado para a multiplicação de comissões administrativas e, por outro, de planos, programas, esquemas diversos de carácter espacial - documentos de urbanismo, por exemplo - ou temporal e/ ou financeiro - programas de desenvolvimento, nomeadamente em matéria de 
A ngelelli \& Saffache

Revista de G estão C osteira Integrada / Journal of Integrated C oastal Z one Management 10(1):65-80 (2010)

Tabela 1. Repartição das competências jurídicas das autoridades públicas na gestão costeira na Martinica. Table 1. Table of distribution of powers of public authorities in coastal management in Martinique.

\begin{tabular}{|c|c|}
\hline D O M IN IOS IN TERESSAD OS & A U T O RIDADES RESPO N SÁVE IS \\
\hline A companhamento dos recursos de pesca e estatísticas. & $\begin{array}{l}\text { G overno central (ministério encarregado da Pesca, assistido pelo Institut } \\
\text { français de recherche pour l'ex ploitation de la mer - IFRE ME R). }\end{array}$ \\
\hline Investigação científica. & $\begin{array}{l}\text { Como financiadores públicos da investigação científica } \\
\text { - União E uropeia (Programa-quadro de investigação e de } \\
\text { desenvolvimento; Fundo E uropeu de D esenvolvimento Regional } \\
\text { (FE D E R); Fundo E uropeu para as Pescas - FE P) } \\
\text { - G overno central (ministério encarregado da Investigação científica) } \\
\text { - Région Martinica (arte. L.4252-1 do código geral das coletividades } \\
\text { territoriais) } \\
\text { Como operadores da investigação científica } \\
\text { - Institut français de recherche pour l'exploitation de la mer (Ifremer) } \\
\text { - Universidade } \\
\text { - Instituto de Investigação para o D esenvolvimento (IRD ). }\end{array}$ \\
\hline Q ualidade das águas marinhas (definição das normas). & União E uropeia \\
\hline $\begin{array}{l}\text { Q ualidade das águas marinhas (controle da aplicação das normas, } \\
\text { acompanhamento e polícia). }\end{array}$ & $\begin{array}{l}\text { Representante local do governo central (Préfet e director regional do } \\
\text { ambiente }+ \text { director do departamento das O bras Públicas + director da } \\
\text { Saúde }+ \text { director regional das A ssuntos marítimos). }\end{array}$ \\
\hline $\begin{array}{l}\text { A utorização das explorações dos recursos vivos no mar (estabelecimentos } \\
\text { de pesca, nomeadamente para a implantação dos reafes). }\end{array}$ & $\begin{array}{l}\text { Région Martinica (art. L.4433-15-1 do código geral das coletividades } \\
\text { territoriais) } \\
\text { (Na prática: representante local do governo central (Préfet de região } \\
\text { sobre proposta do director regional das A ssuntos marítimos). }\end{array}$ \\
\hline Luta contra a poluição no mar (PO LMAR). & $\begin{array}{l}\text { Representante local do governo central (Préfet delegado à acção do } \\
\text { governo central em mar }+ \text { Marinha militar }+ \text { director do departamento } \\
\text { das O bras Públicas). }\end{array}$ \\
\hline Balizagem das zonas no mar. & $\begin{array}{l}\text { Representante local do governo central (Préfet sobre proposta do director } \\
\text { do departamento das O bras Públicas). }\end{array}$ \\
\hline $\begin{array}{l}\text { O rganização dos lazeres náuticos na faixa litoral dos } 300 \text { metros: } \\
\text { protecção dos banhos e regulamento das actividades náuticas praticadas } \\
\text { sem engenhos motorizados. }\end{array}$ & Presidente dos Communes litorais. \\
\hline $\begin{array}{l}\text { O rganização dos lazeres náuticos na faixa litoral dos } 300 \text { metros: } \\
\text { regulamento das actividades náuticas praticadas com engenhos } \\
\text { motorizados. }\end{array}$ & $\begin{array}{l}\text { Representante local do governo central ( Préfet delegado à acção do } \\
\text { governo central em mar + director regional das A ssuntos marítimos). }\end{array}$ \\
\hline Q ualidade das águas de banhos (definição das normas). & União E uropeia. \\
\hline $\begin{array}{l}\text { Q ualidade das águas de banhos (controle da aplicação das normas, } \\
\text { acompanhamento e polícia). }\end{array}$ & Representante local do governo central (director da Saúde). \\
\hline O cupação do domínio público marítimo imergido fora dos portos. & $\begin{array}{l}\text { Representante local do governo central (Préfet sobre proposta do director } \\
\text { do departamento das O bras Públicas). }\end{array}$ \\
\hline $\begin{array}{l}\text { O cupação do domínio público marítimo imergido fora dos portos com } \\
\text { inconveniente para a navegação. }\end{array}$ & $\begin{array}{l}\text { Representante local do governo central (Préfet sobre proposta do director } \\
\text { do departamento das O bras Públicas após pareceres dos serviços da } \\
\text { Marinha militar e dos A ssuntos marítimos). }\end{array}$ \\
\hline $\begin{array}{l}\text { Regulamento da pesca profissional em zona económica (de } 12 \text { à } 200 \\
\text { milhas): zonas de exclusão de pesca; épocas de pesca; espécies; } \\
\text { características dos engenhos; dimensões mínimas de capturas; gestão das } \\
\text { licenças de pesca especiais; limitação das tonelagens exploráveis por } \\
\text { espécies. }\end{array}$ & União E uropeia (D irecção-geral das Pescas). \\
\hline $\begin{array}{l}\text { Regulamento da pesca profissional em mar territorial (de } 0 \text { à } 12 \text { milhas): } \\
\text { zonas de proibição temporária de pesca; navios autorizados e criação e } \\
\text { gestão de um regime de licenças de pesca; épocas de pesca; espécies. }\end{array}$ & $\begin{array}{l}\text { O rganização profissional dos pescadores (Comité régional des pêches } \\
\text { maritimes et des E levages marins) + representante local do governo central } \\
\text { (Préfet de região sobre proposta do director regional dos A ssuntos } \\
\text { marítimos). }\end{array}$ \\
\hline $\begin{array}{l}\text { Regulamento da pesca profissional em mar territorial: zonas de proibição } \\
\text { temporária de pesca; épocas de pesca; espécies. }\end{array}$ & $\begin{array}{l}\text { Région Martinica (artigo L.4433-15-1 do código geral das coletividades } \\
\text { territo riais) (N a prática: representante local do governo central ( Préfet de } \\
\text { região sobre proposta do director regional dos A ssuntos marítim os). }\end{array}$ \\
\hline $\begin{array}{l}\text { Regulamento da pesca profissional em mar territorial: zonas de proibição } \\
\text { de pesca sem limitação de duração; características dos engenhos de } \\
\text { pesca; dimensões mínimas de capturas de certas espécies. }\end{array}$ & $\begin{array}{l}\text { G overno central (ministério encarregado das Pescas, assistido pelo } \\
\text { Institut français de recherche pour l'exploitation de la mer). }\end{array}$ \\
\hline $\begin{array}{l}\text { Regulamento da pesca de lazer: zonas de proibição de pesca; épocas de } \\
\text { pesca; espécies regulam entadas; limitação das quantidades pescadas. }\end{array}$ & $\begin{array}{l}\text { G overno central ou o seu representante local (Préfet de região sobre } \\
\text { proposta do director regional dos A ssuntos marítimos). }\end{array}$ \\
\hline Regulamento de segurança dos navios de pesca. & G overno central (ministério encarregado dos transportes). \\
\hline Regulamento das qu & $\mathrm{m} 0$ \\
\hline
\end{tabular}




\section{(continuação da Tabela 1)}

\begin{tabular}{|c|c|}
\hline $\begin{array}{l}\text { Regulamento da pesca profissional em mar teritorial: zonas de proibição } \\
\text { temporária de pesca; épocas de pesca; espécies. }\end{array}$ & $\begin{array}{l}\text { Régon Martinica (artigo L.4433-15-1 do código geral das coletividades } \\
\text { temitoriais) (Na prática: representante local do governo central (Préfet de } \\
\text { região sobre proposta do director regional dos Assuntos marítimos). }\end{array}$ \\
\hline $\begin{array}{l}\text { Regulamento da pesca profissional em mar teritorial: zonas de proibição } \\
\text { de pesca sem limitação de duração; características dos engenhos de } \\
\text { pesca; dimensões mínimas de capturas de certas espécies. }\end{array}$ & $\begin{array}{l}\text { Governo central (ministério encarregado das Pescas, assistido pelo } \\
\text { Institut frangais de recherche pour l'exploitation de la me). }\end{array}$ \\
\hline $\begin{array}{l}\text { Regulamento da pesca de lazer: zonas de proibição de pesca; épocas de } \\
\text { pesca; espécies regulamentadas; limitação das quantidades pescadas. }\end{array}$ & $\begin{array}{l}\text { Governo central ou o seu representante local (Préft de região sobre } \\
\text { proposta do director regional dos Assuntos marítimos). }\end{array}$ \\
\hline Regulamento de segurança dos navios de pesca. & Governo central (ministério encarregado dos transportes). \\
\hline $\begin{array}{l}\text { Regulamento das qualificações profissionais marítimas para a pesca } \\
\text { (programas, exames e emissão das patentes). }\end{array}$ & $\begin{array}{l}\text { Govemo central (ministério encarregado dos transportes) ou o seu } \\
\text { representante local (Préft de região sobre proposta do director regional } \\
\text { dos Assuntos marítimos). }\end{array}$ \\
\hline Qualidade dos produtos do mar (definição das normas). & $\begin{array}{l}\text { União Europeia (com a Autoridade europeia para segurança dos } \\
\text { alimentos - EFSA). }\end{array}$ \\
\hline $\begin{array}{l}\text { Qualidade dos produtos do mar (controle da aplicação das normas, } \\
\text { acompanhamento e polícia). }\end{array}$ & $\begin{array}{l}\text { Govemo central (ministério encarregado da Alimentação) e o seu } \\
\text { representante local (director dos serviços veterinários). }\end{array}$ \\
\hline Aç̧ões colectivas no sector da pesca e da aquicultura marinha. & $\begin{array}{l}\text { O rganização profissional dos pescadores (Comité régional des pêhhes } \\
\text { maritimes et des Elevages marins). }\end{array}$ \\
\hline $\begin{array}{l}\text { Tutela das organizações profissionais dos pescadores (Comité régonal des } \\
\text { pêthes maritimes et des Elevages marins, sociedades cooperativas; } \\
\text { organizações de produtores). }\end{array}$ & $\begin{array}{l}\text { Governo central ou o seu representante local (Préfet de região sobre } \\
\text { proposta do director regional dos Assuntos marítimos). }\end{array}$ \\
\hline Aplicação dos regulamentos das pescas. & $\begin{array}{l}\text { Representante local do governo central (director regional dos Assuntos } \\
\text { mańtimos, coordenador da acção do govemo central em mar no } \\
\text { domínio das pescas marítimas). }\end{array}$ \\
\hline $\begin{array}{l}\text { Polícia judiciária (investigação e repressão das infracções) em matéria de } \\
\text { pesca. }\end{array}$ & Director regional dos Assuntos marítimos. \\
\hline $\begin{array}{l}\text { Financiamento directo dos investimentos } \\
\text { - frota de pesca artesanal (navios com menos de } 9 \text { metros) } \\
\text { - ajuda às empresas de aquicultura } \\
\text { - concurso ao desenvolvimento económico } \\
\text { - transferência de tecnologia no domínio de pesca e aquicultura. }\end{array}$ & $\begin{array}{l}\text { Région Martinica + União Europeia (representado pelo govemo central } \\
\text { ou seu representante local, o Préfet de região). }\end{array}$ \\
\hline Formação profissional marítima (definição dos programas). & Governo central (ministério encarregado dos transportes). \\
\hline Formação profissional marítima (financiamento). & $\begin{array}{l}\text { Régon Martinica + União Europeia (Fundo Social Europeu, } \\
\text { representado pelo govemo central ou seu representante local, o Préfet de } \\
\text { região. }\end{array}$ \\
\hline $\begin{array}{l}\text { Equipamento dos portos de pesca (infra-estruturas e capacidade de } \\
\text { acolhimento e valonização dos produtos). }\end{array}$ & $\begin{array}{l}\text { Département Martinica + União Europeia (representado pelo o govemo } \\
\text { central ou seu representante local, o Préfet de região sobre proposta do } \\
\text { director regional dos Assuntos marítimos). }\end{array}$ \\
\hline
\end{tabular}

gestão costeira integrada com a multiplicação dos actores públicos exigindo, especialmente desde os anos '90 com o papel crescente da União Europeia, a abordagem transversal e o desenvolvimento de políticas interministeriais (D eboudt et al., 2008) ou de "estratégias integradas".
O terceiro elemento fundamental, que resulta dos dois primeiros, é que as decisões e, em particular, decisões da implantação de recifes artificiais ou, mais geralmente, da gestão costeira, vão ser compromissos representando o "mínimo denominador comum" entre os diferentes interesses. 


\subsection{Divergências dos objectivos ambientais e os objectivos de exploração econômica}

Mais de quarenta países implantaram recifes, quer para aumentar a produção comercial de peixes como o Japão, a China continental, Taiwan, Hong-Kong, as Filipinas, Portugal continental (Neves Santos \& Costa Monteiro, 1998) e Madeira, ou a Itália peninsular e a Sicília (D 'Anna et al., 2004), quer para fins recreativos (Sutton \& Bushnell, 2007) como a Austráliae os Estados Unidos. Q uanto aos objectivos, a União Europeia evoluiu.

Em 1986, os recifes tinham por objectivo facilitar o repovoamento haliêutico e permitir, após um período de interrupção da pesca, uma exploração óptima (União Europeia, 1986).

Em 2000, a revisão da política europeia das pescas prolongava uma dupla orientação que se manifestava a nível das instituições europeias desde os anos ' 80 : a tendência a considerar a gestão das águas costeiras como a resultante da gestão dos territórios adjacentes, e a tendência a privilegiar a abordagem ambiental de conservação "do meio marinho" antes da abordagem económica de exploração "do meio marítimo".

A partir de 2006 a União Europeia passou a incentivar abordagens que procurem "proteger e desenvolver a fauna e a flora aquáticas e que contribuam para melhorar o ambiente aquático" (União E uropeia, 2006).

Por último, a União Europeia reconheceu que 0 seu quadro institucional sobre a água não estava adaptado à protecção do meio marinho e necessitava de um "novo instrumento político" (União Europeia, 2005a) que revestiu a forma da D irectiva-Q uadro dita "Estratégia Marinha" de 2008 (União Europeia, 2008). Supostamente, esta última leva em consideração "as inextricáveis relações que ligam as zonas costeiras e 0 meio marinho" (União Europeia, 2005b), mas confirma a vontade europeia de protecção do ambiente, em vez de exploração económica.

\subsection{Participação dos pescadores profissionais}

0 "mosaico" dos poderes públicos e a fragmentação das decisões (4.1.) e a evolução dos objectivos (4.2.) aumentam a dificuldade de participação dos pescadores profissionais na implantação dos recifes artificiais - e, de maneira mais geral, a dificuldade em integrar os utilizadores do mar num programa de gestão costeira.

Se nos referirmos a uma tipologia de participação adaptada à pesca (Pretty, 1995), numa escala simplificada de sete níveis que vão desde a "mobilização autónoma", onde a comunidade de pescadores toma iniciativas independentes dos poderes públicos mas pode recorrer a apoios externos conservando o controlo, ao extremo oposto "a manipulação" , no qual a participação dos pescadores é de pura forma e as respectivas instâncias desprovidas de poderes reais, a implantação dos recifes artificiais na Martinica poderia ser classificada de nível 3: "a participação consultiva", na qual a comunidade é consultada e os problemas avaliados e analisados por peritos, mas sem obrigação de dar seguimento às consultas...

A fraca capacidade de acção - de financiamento e/ ou autogestão - alegada pelos pescadores profissionais no que se refere à gestão da faixa costeira está na origem da intervenção pública directa de numerosas entidades em matéria de recifes, não só na Martinica, mas também no Languedoc-Roussillon, em Marselha, ou na ilha da Reunião.

Contudo, na Martinica, à semelhança do que sucede noutras ilhas das Penenas Antilhas, esta fraca capacidade é provavelmente intensificada pelo carácter relativamente recente da gestão das pescas, bem como por um forte individualismo ou, no mínimo, por um fraco grau de coesão social (Brown \& Pomeroy, 1999).

Além disso, nas tradições francesas e europeias, 0 mar não tem valor comercial e não pode ser apropriado. Apenas os poderes públicos podem proceder à avaliação e à valorização dos ecossistemas marinhos (Nunes \& Riyanto, 2005). É por isso que o governo central francês e o Conseil Régional pediram ao $\mathrm{C}$ omitérégional des Pêches maritimes et des $\mathrm{E}$ levages marins (CRPMEM) para realizar, sucessivamente, os engenhos de concentração de peixes (1998-2000), os recifes artificiais (2000-2003), as áreas marinhas protegidas (2002-2005), assumindo assim o risco de criar uma situação top-down e suscitar o desinteresse dos pescadores profissionais, risco esse que é intensificado pela ambivalência dos objectivos preservar uma zona de pesca e trocar uma perda imediata por um lucro futuro; perder a utilização privilegiada do mar a favor de outras actividades 
protectoras do ambiente ou recreativas - e a complexidade dos procedimentos de imersão mas também de financiamento.

\section{PERSPECTIVAS DE SOLUÇÕES - CONCLUSÕES}

Paradoxalmente, a complexidade gerada pelas regras da União europeia e dos poderes públicos franceses pode ajudar a simplificar o "mosaico" resultante da superposição de normas nacionais, europeias e internacionais, e melhorar localmente a "governação" (segundo palavra utilizada pelos Regulamentos europeus) das zonas costeiras.

Primeiro, os objectivos da política europeia de criação de recifes artificiais já não se limitam ao aumento dos recursos da pesca, mas tornam-se mais gerais, visando a protecção do meio marinho. Esta nova orientação é susceptível de reunir mais largamente os interesses dos utentes da zona costeira que a antiga orientação (crescimento dos recursos de pesca) que era limitada aos pescadores.

Depois, estes mecanismos europeus de apoio através de programas manifestam duas tendências importantes: um incentivo financeiro intenso eamplo, e um mecanismo de iniciativa e de implementação descentralizado.

Com efeito, e em conformidade com os princípios europeus de subsidiariedade e de parceria, os Programas europeus não são estabelecidos pelaUnião Europeia mas pelos governos centrais "após uma consulta estreita dos parceiros económicos e sociais e dos parceiros aos níveis regionais e locais do sector da pesca, bem como de todos os organismos competentes".

Neste contexto, a intervenção da União Europeia, apesar do suplemento de procedimentos e dos prazos que ela gera é uma oportunidade.

Em primeiro lugar, tanto a fragmentação das competências dos poderes públicos, como a existência de interesses privados ou colectivos ao lado do interesse geral são os dados de base da gestão costeira, apelando precisamente um esforço de intregração. O ra, através dos programas incitativos, a União Europeia aceita estes dados, sem impor a sua vontade na concepção ou implementação de políticas.

Em segundo lugar, os próprios programas europeus fornecem um quadro de integração aos actores da zona costeira. Com a sua relativa flexibilidade - no que respeita ao conteúdo das acções, aos beneficiários, aos modos de associação e aos trabalhos das diferentes comissões técnicas e das comissões de programação dos fundos públicos - e o seu carácter descentralizado, todas as instituições públicas e a maior parte dos grupos de pressão que intervêm na faixa costeira podem participar na definição de uma política local. Por outro lado, a montagem de um programa geral ou de um pedido de concurso financeiro da União Europeia impõe aos actores públicos, ou privados, um esforço de conceptualização dos projectos, de planificação, de busca de parcerias financeiras ou operacionais e de consenso local. Basicamente, a investigação dos fundos europeus permite criar uma capacidade para decidir localmente e os programas europeus fornecem num contexto de "mosaico" uma espécie de "gramática" às ideias e aos projectos locais permitindo a sua formulação.

Em terceiro lugar, o próprio aporte financeiro europeu é determinante para os projectos de recifes - ou, mais amplamente, de gestão costeira nas pequenas economias insulares.

No fundo, a União Europeia, através das características da sua intervenção na Martinica, pode aparecer sob certos aspectos como uma máquina para fabricar políticas locais e consensos, sobretudo num contexto onde os poderes públicos são múltiplos, $\mathrm{e}$ geralmente externos.

\section{CONCLUSÕES}

O s recifes artificiais em Martinica podeniam ilustrar a desintegração da zona costeira. Viu-se que os objectivos a atingir e, por conseguinte, os resultados podem ser diferentes; que os processos de decisão em Martinica são complexos e reflectem um "mosaico" dos poderes; que a União Europeia persegue objectivos paralelos ou mesmo divergentes de proteç̧ão do ambiente e exploração racional dos recursos; que emprega para o efeito os meios que vão da regulamentação ao apoio financeiro e, por último, que parece deixar ainda mais autonomia às instâncias de decisão locais (na iniciativa e na realização: "bottom-up").

Apesar destas numerosas indeterminações, 0 método europeu oferece nas regiões ultraperiféricas 
um verdadeiro instrumento de "gestão integrada". Fornece aos diferentes interesses que agem na zona costeira um quadro relativamente flexível. Este permite atingir os objectivos escolhidos localmente, tanto quanto são compatíveis com as diferentes políticas marítimas europeias.

A gestão integrada na Martinica, como no territorio continental da União Europeia - tendente nomeadamente a estabelecer uma unidade institucional do meio marinho -, pode ser obtida paradoxalmente por um suplemento de procedimentos e a utilização de instrumentos complexos a conhecer e executar ("programas plurianuais", "programas-quadro", "programas operacionais", "iniciativas comunitárias", "fundos estruturais", "instrumentos financeiros", que se inserem em "estratégias comuns" ou prolongando "diretivas-quadro", etc.).

Por conseguinte, doravantea dificuldade é que este instrumento de gestão integrada seja apropriado por todos os actores e não apenas pelas instituições que compartilham uma gestão "desintegrada" da zona costeira. Para além dos recifes artificiais, um ponto essencial permanece em relação às zonas costeiras insulares que estão expostas a pressões na utilização dos recursos e que estas pressões são por vezes exacerbadas por formas inadequadas de intervenção de gestão (Krelling et al., 2008). Será que a União Europeia vai permitir aos actores locais resolver este problema?

\section{BIBLIOGRAFIA}

Baine, M. (2001) - Artificial reefs: A review of their design, application, management and performance. 0 cean \& C oastal M anagement. 44, 241259.

Barnabé, G. (2007) - Suivi scientifique de quatre récifs artificiels en M artinique- Rapport final pourl'année 2006. Conseil Régional de la Martinique, 22p., Schoelcher, Martinique. (não publicado).

Brown, D. N. \& Pomeroy, R. S. (1999) - Comanagement of Caribbean Community (CARICO M) fisheries. M arine Policy, Vol. 23, $n^{\circ} 6$, 549-570.

D’Anna, G., Giacalone, V.M., Badalamenti, F. \& Pipitone, C. (2004) - Releasing of hatchery-reared juveniles of the white seabream Diplodus sargus
(L., 1758) in the Gulf of Castellammare artificial reef area (NW Sicily). A quaculture. 233, 251-268.

D auvin, J.-C., Lozachmeur, O., Capet, Y., D ubrulle, J.-B., G hezali, M. \& Mesnard, A.H. (2004) - Legal tools for preserving France's natural heritage through integrated coastal zone management. 0 cean \& C oastal M anagement.47, 463-477.

D eboudt, P., Dauvin, J-C., Lozachmeur, O. (2008) Recent developments in coastal zone management in France: The transition towards integrated coastal zone management (1973-2007). 0 œan \& C oastal Management. 51, 212-228.

D esse, M. \& Saffache, P. (2005) - L es littoraux antillais: des enjeux del'aménagement à la gestion durable, Matoury (Guiana Francesa). Ibis Rouge Editions, pp.90 \& ss.

D owling, R.K. \& Nichol,J. (2001) - The HMAS Swan artificial dive reef. A nnals of Tourism Research. Vol.28, n²1, 229-232.

Ehler, C.N. (2003) - Indicators to measure governance performance in integrated coastal management. 0 cean \& C oastal M anagement. 46, 335-345.

G overno francês (1985) - Artigo R.123-1, código do ambiente e Anexo I (16º ao artigo R.123-1.

Governo francês (2000) - Artigo 47, lei de 13 de dezembro de 2000, sobre a orientação para ultramarino - tornado o artigo L.4433-15-1 do código geral das coletividades territoriais.

Krelling, A.P., Polette, M. \& Casillas DelValls, A. (2008) - CoastLearn: Lessons learnt from a webbased capacity building in Integrated Coastal Zone Management (ICZM). 0 can \& C oastal M anagement. 51, 789-796.

Laisné, L. \& Angelelli, P. (2000) - Mise en place et exploitation des DCP en Martinique: Aspects réglementaires et économiques, In: Le Gall, J.-Y., Cayré, P. \& Taquet, M. (eds), Pêche thonière et dispositifs de concentration depoissons. Collection "Actes de Colloques" n²8, E ditions Ifremer, França.

Morton, B. (1996) - Artificial reefs, Fish and Cyanide. M arine Pollution Bulletin. Vol.32 (7), 522-523.

Moutamalle L., Saffache P., Dehoorne O. (2006) De l'aménagement du territoire à la gestion intégrée: l'exemple de la Caraibe. La G éographie (A ca $\mathrm{G}$ eographica), 1522 - número fora de série, $\mathrm{p}$. 5-7. 
Nações Unidas (1982 a) - Art. $1^{\circ}, \S 1$, (4) da Convenção das Nações Unidas sobre o Direito do Mar, do 10 de dezembro de 1982: «Para efeitos da presente Convenção: [... ] (4) 'poluição do meio marinho' significa a introdução pelo homem, direta ou indiretamente, de substâncias ou de energia no meio marinho, incluindo os estuários, sempre que a mesma provoque ou possa vir provocar efeitos nocivos, tais como danos aos recursos vivos e à vida marinha, riscos à saúde do homem, entrave às atividades marítimas, incluindo a pesca e as outras utilizações legítimas do mar, alteração da qualidade da água do mar, no que se refere à sua utilização, e deterioração dos locais de recreio».

Nações Unidas (1982 b) - Artigo $1^{\circ} \S 1$, (5), a, ii), Convenção das Nações Unidas sobre o Direito do Mar, celebrada em 1982.

Nações Unidas (1982 c) - Artigo 193, Convenção das Nações Unidas sobre o Direito do Mar, celebrada em 1982.

Nações Unidas (1982 d) - Artigo 210 §1, Convenção das Nações Unidas sobre o Direito do Mar, celebrada em 1982.

Neves Santos, M. \& Costa Monteiro, C. (1998) Comparison of the catch and fishing yield from an artificial reef system and neighbouring areas off Faro (Algarve, South Portugal). Fisheries Research. 39, 55-65.

Nunes, P.A.L.D. \& Riyanto, Y. (2005) - Information as a regulatory instrument to price biodiversity benefits: certification and ecolabeling policy practices. Biodiversity C onservation. 14, 2009-2027.

O ren, U. \& Benayahu, Y. (1997) - Transplantation of juvenile corals: a new approach for enhancing colonization of artificial reefs. M arine Biology. 127, 499-505.

Pary, B. (2004) - Réaifs artificiels en L anguedoc-Roussillon: des outils originaux d'aménagement de la bande ôtière, 13p. < http:/ / www.museum.agropolis.fr/ pages/ savoirs/ littoral/ Pary.pdf >. Acedido em Abr09.

Pomeroy, R.S., McConney, P. \& Mahon, R. (2004) Comparative analysis of coastal resource comanagement in the Caribbean, 0 can \& Coastal M anagement. 47, 429-447.

Pretty, J.N. (1995) - Participatory learning for sustainable agriculture. W orld D evelopment. 23(8), 1247-63, cite par Silver, J.J. \& Campbell, L.M.
(2005) - Fisher participation in research: D ilemmas with the use of fisher knowledge. 0 can \& C oastal M anagement. 48, 721-741.

Seaman, W. (2007) - Artificial habitats and the restoration of degraded marine ecosystems and fisheries. H ydrobiologia. 580, 143-155.

Singh, A. \& Mee, L. (2008) - Examination of policies and MEAs commitment by SID S for sustainable management of the Caribbean Sea. Marine Policy. 32, 274-282.

Sutton, S. G., \& Bushnell, S. L. (2007) - Socioeconomic aspects of artificial reefs: Considerations for the G reat Barrier Reef Marine Park. 0 cean \& C oastal M anagement. 50, 829-846.

Sygut, A. (2006) - E valuation de l'effet de zones marines protégées en Martinique sur le peuplement de poissons Rapport final - octobre 2006. BioMerEnvironnement/ União E uropeia (Instrumento Financeiro de O rientação das Pescas) , 137p., Martinica. (não publicado).

Ten Voorde, M., Da G raça Neves, M. \& Antunes do Carmo, J.S. (2008) - Estudo Preliminar da Geometria de um Recife Artificial para Protecção Costeira e para a Prática de Surf na Costa O este Portuguesa. Revista da G estão Costeira Integrada. 8 (1), 65-79.

União Europeia (1976 a) - Directiva 76/ 160/ CEE do Conselho, de 8 de D ezembro de 1975, relativa à qualidade das águas balneares, e D irectiva 2006/ 7/ CE do Parlamento Europeu e do Conselho de 15 de Fevereiro de 2006 relativa à gestão da qualidade das águas balneares e que revoga a Directiva 76/ 160/ CEE.

União Europeia (1976 b) - Directiva 76/ 464/ CEE do Conselho, de 4 de Maio de 1976, relativa à poluição causada por determinadas substâncias perigosas lançadas no meio aquático da Comunidade.

União Europeia (1979) - Directiva 79/ 923/ CEE do Conselho, de 30 de Outubro de 1979, relativa à qualidade exigida das águas conquícolas, codificada recentemente pela Directiva 2006/113/ CE do Parlamento europeu e do Conselho, do 12 de dezembro de 2006.

União Europeia (1983) - Regulamento (CEE) n¹70/ 83 do Conselho, de 25 de Janeiro de 1983, que institui um regime comunitário de conservação e de gestão dos recursos da pesca. 
União Europeia (1986) - Regulamento (CEE) nº 4028/ 86 do Conselho de 18 de D ezembro de 1986 relativo a acções comunitárias para 0 melhoramento e a adaptação das estruturas do sector da pesca e da aquicultura.

União Europeia (1991 a) - Directiva 91/ 271/ CEE do Conselho, de 21 de Maio de 1991, relativa ao tratamento de águas residuais urbanas.

União Europeia (1992) - Directiva 92/ 43/ CEE do Conselho, de 21 de Maio de 1992, relativa à preservação dos habitats naturais e da fauna e da flora selvagens.

União Europeia (1997) - Artigo $6^{\circ}$, Tratado que instituia Comunidade Europeia(Versão compilada 1997).

União Europeia (1999) - Regulamento (CE) n 2792/ 1999 do Conselho, de 17 de D ezembro de 1999, que define os critérios e condições das acções estruturais no sector das pescas.

União Europeia (2000 a) - Artigo $2^{\circ} \S 7$, D irectiva 2000/60/ CE do Parlamento Europeu e do Conselho, de 23 de Outubro de 2000, que estabelece um quadro de acção comunitária no domínio da política da água (D irectiva-Q uadro no domínio da água).

União Europeia (2000 c) - $9^{\circ}$ "Considerando», Directiva 2000/60/ CE (D irectiva-Quadro no domínio da água).

União Europeia (2005 a) - Comunicação da Comissão Europeia em 24 de O utubro de 2005 "Estratégia temática para a protecção e conservação do meio marinho" - COM(2005) 504 final.
União Europeia (2005 b) - pagina 8, Comunicação da Comissão Europeia em 24 de O utubro de 2005 ao Conselho e ao Parlamento - Europeu "Estratégia temática para a protecção e conservação do meio marinho" - CO M(2005) 504 final.

União Europeia (2006) - Regulamento (CE) n 1198/ 2006 do Conselho, de 27 de Julho de 2006, relativo ao Fundo Europeu das Pescas.

União Europeia (2007) - Artigo $16^{\circ}$, Regulamento (CE) n 498/ 2007 da Comissão, de 26 de Março de 2007 , que estabelece as normas de execução do Regulamento (CE) n¹198/ 2006 do Conselho relativo ao Fundo Europeu das Pescas.

União Europeia (2008) - Directiva 2008/ 56/ CE do Parlamento Europeu e do Conselho, de 17 de Junho de 2008 que estabelece um quadro de acção comunitária no domínio da política para o meio marinho (D irectiva-Q uadro "Estratégia Marinha").

Van Treeck, P. \& Schuhmacher, H. (1998) - Mass D iving Tourism : A new dimension calls for new management approaches. Marine Pollution Bulletin. Vol.37 (8-12) 499-504.

Whitmarsh, D. (1997) - Artificial Reefs: the Law and the Profits. M arine Pollution Bulletin. Vol. 34 (1) 23.

Whitmarsh, D., Neves Santos, M., Ramos, J. \& Costa Monteiro, C. (2008) - Marine habitat modification through artificial reefs off the Algarve (southern Portugal): An economic analysis of the fisheries and the prospects for management. 0 cean \& C oastal Management, 51, 463-468. 